\title{
Nutritional regulation of genome-wide association obesity genes in a tissue-dependent manner
}

Piriya Yoganathan ${ }^{1}$, Subashini Karunakaran ${ }^{1}$, Maggie $\mathrm{M} \mathrm{Ho}^{1}$ and Susanne M Clee ${ }^{1,2^{*}}$

\begin{abstract}
Background: Genome-wide association studies (GWAS) have recently identified several new genetic variants associated with obesity. The majority of the variants are within introns or between genes, suggesting they affect gene expression, although it is not clear which of the nearby genes they affect. Understanding the regulation of these genes will be key to determining the role of these variants in the development of obesity and will provide support for a role of these genes in the development of obesity.
\end{abstract}

Methods: We examined the expression of 19 GWAS obesity genes in the brain and specifically the hypothalamus, adipose tissue and liver of mice by real-time quantitative PCR. To determine whether these genes are nutritionally regulated, as may be expected for genes affecting obesity, we compared tissues from fasting and non-fasting animals and tissues from mice consuming a high fat high sucrose diet in comparison to standard rodent chow.

Results: We found complex, tissue-dependent patterns of nutritional regulation of most of these genes. For example, Bat2 expression was increased $~ 10$-fold in the brain of fed mice but was lower or unchanged in the hypothalamus and adipose tissue. Kctd15 expression was upregulated in the hypothalamus, brain and adipose tissue of fed mice and downregulated by high fat feeding in liver, adipose tissue and the hypothalamus but not the remainder of the brain. Sh2b1 expression in the brain and Faim2 expression in adipose tissue were specifically increased $>20$-fold in fed mice. Tmem 18 expression in adipose tissue but not the brain was reduced $80 \%$ by high fat feeding. Few changes in the expression of these genes were observed in liver.

Conclusions: These data show nutritional regulation of nearly all these GWAS obesity genes, particularly in the brain and adipose tissue, and provide support for their role in the development of obesity. The complex patterns of nutritional and tissue-dependent regulation also highlight the difficulty that may be encountered in determining how the GWAS genetic variants affect gene expression and consequent obesity risk in humans where access to tissues is constrained.

Keywords: Obesity genes, Genome-wide association, Gene expression, High fat diet, Feeding and fasting, Gene-diet interaction, Adipose tissue, Brain

\footnotetext{
* Correspondence: susanne.clee@ubc.ca

'Department of Cellular and Physiological Sciences, University of British

Columbia, Vancouver, BC, Canada

${ }^{2}$ Life Sciences Institute, Department of Cellular and Physiological Sciences,

University of British Columbia, 2350 Health Sciences Mall, Vancouver, BC V6T

1Z3, Canada
}

\section{Biomed Central}

(c) 2012 Yoganathan et al.; licensee BioMed Central Ltd. This is an Open Access article distributed under the terms of the Creative Commons Attribution License (http://creativecommons.org/licenses/by/2.0), which permits unrestricted use, distribution, and reproduction in any medium, provided the original work is properly cited. 


\section{Background}

Advances in our understanding of the genetic contribution to obesity have come from recent genome wide association studies (GWAS). GWAS have identified several new genetic variants associated with obesity and its related traits such as body mass index (BMI). Most prominent amongst these are SNPs within FTO, which have the strongest effects on obesity risk [1-5]. Additional studies, including large scale meta-analyses, discovered additional variants associated with obesityrelated traits that have now been replicated [5-7]. These include SNPs within or near MC4R, CTNNBL1, NPC1, MAF, PTER, PRL, SH2B1, NEGR1, the SEC16BRASAL2 region, TMEM18, the SFRS10-ETV5-DGKG region, BDNF, FAIM2, KCTD15, the NCR3-AIF1-BAT2 region, GNPDA2, and $M T C H 2$ [8-11].

Alterations in a few of these genes have previously been shown to affect body weight [12-16]. Melanocortin 4 receptor, $M C 4 R$, mutations are the most common cause of monogenic severe obesity and missense variants within the gene have been associated with altered risk for common obesity $[16,17]$. Brain derived neurotrophic factor, $B D N F$, regulates feeding, its expression is altered by consumption of high fat diet, and variants within the gene have previously been associated with obesity $[13,14,16,18]$. Sh $2 b 1$ knockouts are obese, and this gene is known to play important roles in leptin signalling $[15,19]$. Understanding the site of action and function of these new obesity genes may provide valuable insight into the pathogenesis of obesity. However, despite the extensive investments in GWAS studies, to date studies of the biology of these genes have been limited. Little is known about most of these GWAS obesity genes and their role in the regulation of body weight is unknown. A better understanding of these genes is needed to capitalize on the information generated by the GWAS.

The SNPs identified by the GWAS generally do not affect the amino acid sequence of the mature protein. They are typically intronic or intergenic. The location of these SNPs suggests they likely affect the regulation of the gene they are located within or of nearby genes, and in some cases it is not clear which of the nearby genes they may be affecting $[7,8,11,20]$. Regulation of a gene may also be tissue specific, or occur in response to certain physiological states. Many genes involved in the regulation of energy homeostasis are metabolically regulated [21-24]. Expression of FTO was shown to be regulated by feeding and fasting in the hypothalamus [25]. Thus we hypothesize that if these GWAS genes affect the development of obesity they may be nutritionally regulated.

Knowledge of the regulation of the GWAS obesity genes is critical for understanding how the associated SNPs alter the function of their cognate genes and thus how these genes may affect the development of obesity. This requires knowledge of the tissues where the gene is normally expressed and an understanding of the physiological processes that regulate it. We sought to determine whether metabolic factors affect the regulation of the newly discovered obesity genes. We examined the regulation of these genes by feeding/fasting status and by the consumption of a diet high in fat and sugar. Here we show that most of the recently identified obesity genes are regulated by dietary status, providing support for their role in processes relevant to the development of obesity. These patterns of regulation were often tissue-dependent and largely unique for each gene, suggesting that many of these genes affect distinct pathways in the development of obesity and that analysis of the effects of the GWAS SNPs on gene expression may need to be performed in all physiologically relevant tissues and under multiple physiological contexts.

\section{Methods}

\section{Animals}

Animals were housed in an environmentally controlled facility with 14 hour light cycles $(7 \mathrm{am}-9 \mathrm{pm})$. Female C57BL/6 J mice were given free access to water and either a standard rodent chow (LabDiet 5010, PMI Nutrition, St. Louis MO, USA) or a diet containing $60 \%$ calories from fat (primarily lard) and 20\% calories from sugar (sucrose and maltodextrin; D12492, Research Diets, New Brunswick NJ, USA) from weaning. This high fat diet has a cholesterol content of $300.8 \mathrm{mg} / \mathrm{kg}$ from the lard. The mice were sacrificed by $\mathrm{CO}_{2}$ asphyxiation at 8 weeks of age. Tissues were rapidly dissected and immediately placed in liquid nitrogen then stored at $-80^{\circ} \mathrm{C}$. Prior to sacrifice, animals were either fasted 4 hours $(9$ am $-1 \mathrm{pm})$ or dissections were performed at 9 am without prior removal of food ("fed"). All procedures were approved by the UBC Committee on Animal Care and were performed according to Canadian Council on Animal Care guidelines.

\section{RNA extraction and CDNA synthesis}

Prior to extraction, tissue samples were cut into small pieces and placed in RNA Later Ice (Applied Biosystems, Carlsbad CA, USA) at $-20^{\circ} \mathrm{C}$ for at least 24 hrs. RNA was extracted using a commercially available kit (E.Z.N.A. ${ }^{\mathrm{Tu}}$ Total RNA II, Omega Biotek, Norcross GA, USA). The integrity of the RNA was verified by performing formaldehyde denaturing agarose gel electrophoresis for all samples except the hypothalamus, for which too little RNA was obtained. Following DNAse I digestion (Fermentas, Burlington ON, Canada) to remove any contaminating genomic DNA, cDNA synthesis (RevertAid First Strand cDNA Synthesis Kit, Fermentas, Burlington ON, Canada) was performed using $1 \mu \mathrm{g}$ of RNA with mixed 
oligo-dT and hexamer primers $(20 \mathrm{ng} / \mu \mathrm{L}$ oligo-dT, $3.6 \mathrm{ng} / \mu \mathrm{L}$ random hexamer final concentration) according to the manufacturer's directions. RNA was subsequently removed with RNase $\mathrm{H}$ digestion (Fermentas, Burlington ON, Canada). Successful cDNA synthesis was verified by PCR amplification of our control genes and visualization of a band of the appropriate size on an agarose gel.

\section{Gene expression}

We examined the dietary regulation of Aif1, Bat2, C10orf97, Ctnnbl1, Dgkg, Etv5, Faim2, Gnpda2, Kctd15, Maf, Mtch2, Negr1, Npc1, Pter, Rasal2, Sec16b, Sfrs10, Sh2b1, and Tmem18. Primer sequences are provided in Additional file 1 Table S1. When there were possible alternatively spliced forms identified in the UCSC genome browser (www.genome.ucsc.edu), we designed the primers in regions common to all isoforms. All primer pairs spanned an intron. Ncr3 is a pseudogene in mice. It does not encode a functional protein due to the presence of premature stop codons [26] and was not examined in our studies.

Relative gene expression was measured using a StepOne Plus real time thermocycler (Applied Biosystems Inc., Carlsbad CA, USA), using SYBR green I for detection (PerfeCTa SYBR Green FastMix, VWR International, Edmonton $\mathrm{AB}$, Canada). Forty cycles of amplification were performed followed by melt-curve analysis for verification that only a single product was amplified from each sample. This verification was also performed by direct visualization of PCR amplification products on an agarose gel. Baseline correction, threshold setting, and calculation of the $\mathrm{Ct}$ value were performed automatically by the StepOne software (version 2.1, Applied Biosystems, Carlsbad CA, USA).

Cyclophilin (Ppib) was chosen as the reference gene, as it proved most robust to changes in expression by experimental condition across each of the tissues in comparison to beta-actin (Actb), Gapdh, and Arbp. This control gene was included on several plates contemporaneous with the genes being assessed, and for each sample the average value of this gene across its multiple replicates was used for normalization of that sample. Delta $C t(\Delta C t)$ values were calculated by subtracting the cycle threshold $(\mathrm{Ct})$ value for each gene from this average value. Delta delta $\mathrm{Ct}(\Delta \Delta \mathrm{Ct})$ values were calculated for each sample by subtracting its $\Delta \mathrm{Ct}$ value from the average $\Delta \mathrm{Ct}$ for the chow-fed, fasted controls in the same experiment. Initially, single measurements were made for each sample ( $n=5$ per dietary group). When there was a potential difference between groups, replicate experiments were performed, including additional samples (up to 10 animals per group). The numbers vary for each tissue and gene because of poor-quality or low yields of RNA obtained from some samples and the number of samples with sufficient RNA available at the time for analysis. For each sample, the average $\Delta \Delta \mathrm{Ct}$ of all its replicates across experiments was used for statistical analysis.

\section{Statistical analysis}

Our study was comprised of three groups: chow-fed mice fasted prior to tissue collection (controls); chowfed mice not fasted prior to tissue collection, "fed"; and high fat diet-fed mice that were fasted prior to tissue collection. The average $\Delta \Delta \mathrm{Ct}$ values of the high fat-fed and fed groups were compared to that of the fasted chow-fed control group and the significance of each assessed by a non-parametric Mann-Whitney U test because of the small sample size. Because this results in two comparisons for each gene (chow-fed, fasted vs. non-fasted mice; fasted chow-fed vs. fasted high fat dietfed mice), the resulting P-values were subsequently Bonferroni corrected by multiplying them by 2 . This approach was chosen over a Kruskal-Wallis test because the comparison between chow-fed "fed" mice and fasted high fat diet-fed mice that is accounted for in the Kruskal-Wallis test is not meaningful. The average fold change for each group shown in the figures was calculated as $2^{\text {-average }} \Delta \Delta \mathrm{Ct}$, with the error bars as $2^{\text {-average }} \Delta \Delta \mathrm{Ct} \pm$ its SE [27].

\section{Results}

\section{Regulation of GWAS obesity genes by dietary status in hypothalamus}

All 19 of the GWAS genes we examined were expressed in the hypothalamus. Many were regulated by either feeding/fasting or by consumption of the high fat diet (Figure 1), but only two genes, Kctd15 and likely Mtch2, were regulated by both conditions. The expression of many genes was increased in non-fasted animals. Kctd15 expression was increased 2.1-fold in fed animals, C10orf97 expression was increased 2.3-fold, and expression of Sfrs 10 was also increased an average of 2.2-fold. The expression of Pter was increased 1.6-fold, and we detected a 1.8-fold increase in Gnpda2 expression. In addition, Ctnnbl1 expression was increased an average of 1.5-fold, although this did not reach statistical significance. Similarly, the expression of Mtch2, Faim2 and $D g k g$ were also increased in the fed mice compared to fasted, however due to the large variability in expression levels, these were not significant.

In contrast to the small differences in gene expression observed in fed compared to fasted animals, chronic feeding of a high fat diet resulted in substantial changes in expression (Figure 1). Kctd15 was decreased a marked 20 -fold in animals consuming a high fat diet (i.e. expression was $\sim 5 \%$ of that seen in chow-fed, fasted control 


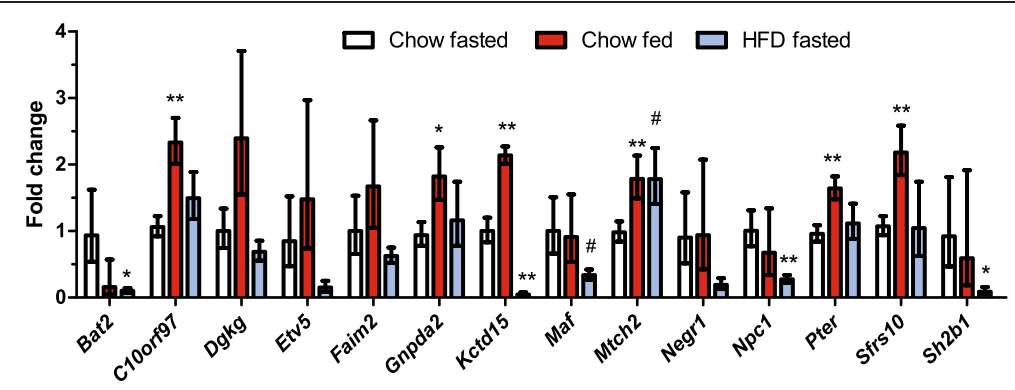

Figure 1 Regulation of GWAS obesity genes in the hypothalamus in the fed state and by high fat feeding. Open bars represent the chow-fed, fasted controls; red bars represent the chow-fed non-fasted group; and blue bars represent the high fat fed group (fasted prior to tissue collection). The number of mice in the chow fasted, chow fed, and HFD fasted groups were: Bat2 $(10,5,7), C 10$ orf $97(10,7,5)$, Dgkg $(4,5,5), \operatorname{Etv5}(10,7,7)$ Faim2 $(4,5,5), \operatorname{Gnpda2}(9,9,6), \operatorname{Kctd} 15(7,5,6), \operatorname{Maf}(7,7,7), \operatorname{Mtch2}(10,9,7)$, Negr1 $(10,7,7), \operatorname{Npc1}(10,5,7)$, Pter $(10,8,6)$, $\operatorname{Sfr} 10(10,7,5)$ and $\operatorname{Sh} 2 b 1(9,6,7)$, respectively. P-values vs. the chow-fed fasted controls: ${ }^{*}<0.05,{ }^{* *}<0.01,{ }^{*}<0.1$.

mice). Bat2 and Sh2b1 mRNA levels were decreased $\sim 10$-fold in animals fed the high fat diet. Npc1 gene expression was decreased by $\sim 4$-fold. Maf expression was $\sim 3$-fold lower, but due to the high variability in the control group did not quite statistical significance after Bonferroni correction. Expression of Etv5 and Negr1 was only $15 \%$ and $19 \%$, respectively, of that observed in controls, although neither reached statistical significance. Mtch2 was the only gene that had increased expression with high fat feeding in the hypothalamus. We did not observe any significant changes in hypothalamic gene expression with feeding or consumption of a high fat diet for Aif1, Dgkg, Faim2, Rasal2, Sec16b or Tmem18 (not shown).

\section{Regulation of GWAS genes by dietary status in whole brain excluding hypothalamus}

Many regions of the brain outside the hypothalamus are also important for the regulation of food intake and energy balance [28]. We detected expression of all 19 genes in these other regions of the brain. Similar to the hypothalamus, the expression of many genes differed between the fasted and fed groups (Figure 2). In contrast to the hypothalamus, however, the changes in expression were often much larger and occurred primarily in non-fasted animals. Most notably, expression of Kctd 15 and Sh $2 b 1$ were increased $>20$-fold, and expression levels of Bat2, Etv5, Negrland Tmem18 were increased $\sim 10$-fold in the fed group. Changes in Kctd15 expression likely did not reach statistical significance due to a large variability in the increase in expression. While the magnitude was variable, most samples had at least 15 -fold increased Kctd15 expression. Feeding was also associated with a 2 to 4 fold increase in the expression of Sec16b, Rasal2, and Npc1. We observed similar trends in the expression of Maf that did not reach statistical significance.

In marked contrast to what was observed in the hypothalamus where several genes were substantially downregulated by high fat feeding, the expression of only a single gene in the remainder of the brain was altered by high fat feeding. Expression of Faim2 was reduced 50\% in the high fat-fed group compared to the chow-fed mice (Figure 2). We did not observe any differences in the expression of Aif1, Mtch2, Dgkg, Sfrs10, Pter, Ctnnbl1, Gnpda2 or C10orf97 under any condition in the remainder of the brain (not shown).

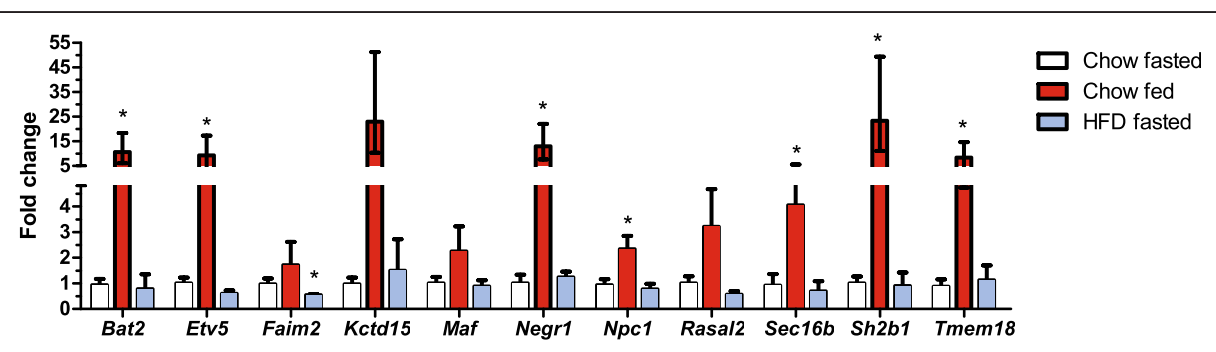

Figure 2 Regulation of GWAS obesity genes in the remainder of the brain in the fed state and by high fat feeding. Open bars represent the chow-fed, fasted controls; red bars represent the chow-fed non-fasted group; and blue bars represent the high fat fed group (fasted prior to tissue collection). The number of mice in the chow fasted, chow fed, and HFD fasted groups were: Bat2 $(7,10,5)$, Etv5 $(7,10,7)$ Faim2 (7, 10, 7), $\operatorname{Kctd15}(5,10,5), \operatorname{Maf}(7,10,7), \operatorname{Negr1}(7,10,5), \operatorname{Npcl}(7,10,5), \operatorname{Rasal2}(7,10,6), \operatorname{Sec} 16 b(7,10,5), \operatorname{Sh} 2 b 1(7,10,7)$, and Tmem18 (7, 10, 5), respectively. ${ }^{*} \mathrm{P}<0.05$ vs. the chow-fed fasted controls. 


\section{Regulation of GWAS genes by dietary status in adipose tissue}

All the GWAS genes we assessed were also expressed in white adipose tissue. Several GWAS obesity genes were highly differentially regulated in adipose tissue from high fat-fed compared to chow-fed mice. Many genes had reduced expression in high fat diet-fed mice (Figure 3). Most strikingly, we observed a $\sim 10$-fold reduction in expression of Negr1 in the high fat-fed mice compared to the chow-fed controls. Etv5 and Kctd15 were also markedly downregulated in mice consuming the high fat diet ( $~ 8$-fold and 5-fold, respectively). Decreased expression of Maf, Npc1, Rasal2, Sec16b, Sh2b1, and Tmem18 in high fat diet-fed mice ranged from $\sim 2.5$-fold for $N p c 1$ to 6-fold for Rasal2. We observed a similar decrease in Bat2 expression with high fat feeding (3-fold), although this did not reach statistical significance. In contrast, Aif1 had a small but significant increase in gene expression in adipose tissue of the mice fed a high fat diet (2.1-fold).

We found the expression of three genes changed significantly by feeding status in adipose tissue. Faim 2 was upregulated a remarkable 20-fold in fed versus fasted mice consuming normal chow (Figure 3). Expression of Mtch2 was increased an average of 8-fold and Kctd15 was increased $\sim 5$-fold in fed animals. A similar trend was observed for Etv5, which had 4-fold higher expression in adipose tissue of fed mice. Smaller increases were observed for Dgkg and Negrl (3.5 and 2.3-fold, respectively), but these were not significant. We did not detect any significant differences in gene expression for Dgkg, Ctnnbl1, Sfrs10, Bat2, Pter, Gnpda2, or C10orf97 in either group.

\section{Regulation by dietary status in liver}

Of the 19 genes we assessed, all except Faim2 and Negr1 were expressed in the liver. In contrast to the tissues above, we observed few differences in gene expression in the liver (Figure 4). Expression of Kctd15 was decreased an average of 20-fold in high fat diet-fed mice compared to chow-fed mice, and was the only gene for which significant differences were detected. Sh2b1 expression was decreased by a similar amount but was not significant $(\mathrm{P}=0.14)$ likely due to the variability of the controls. Rasal2 expression was decreased an average 3.4-fold in the high fat diet-fed mice. Expression of Gnpda2 was decreased 2-fold in the high fat-fed mice, and by a similar amount in fed animals compared to fasted. Similarly, Npc1 expression was decreased an average 2.6-fold in fed animals compared with fasted. Interestingly, expression of $D g k g$ was low but detectable in both groups of chow-fed mice, whereas expression could not be detected in five of six high fat diet-fed mice. No differences were observed in the expression of the other genes expressed in liver (Sec16b, Maf, Mtch2, Tmem18, Aif1, Bat2, Sfrs10, Pter, Ctnnbl1, Etv5, and C10orf97) in response to fed status or consumption of the high fat diet.

\section{Discussion}

GWAS have identified many new SNPs associated with the development of obesity. Most of these SNPs are located in introns or intergenic regions, suggesting they affect the regulation of the corresponding gene or nearby gene(s), but which gene or genes they affect is unknown. Little is known about most of these genes or how they may affect the development of obesity, but understanding their regulation is a key step that may provide important clues. Many genes involved in metabolism and maintaining energy balance are regulated in response to feeding and fasting or by dietary components. Identification of such regulatory patterns would provide support for a potential role in the development of obesity. To begin to understand the regulation of the GWAS obesity genes and if they are nutritionally regulated we examined how changes in dietary conditions affect their expression.

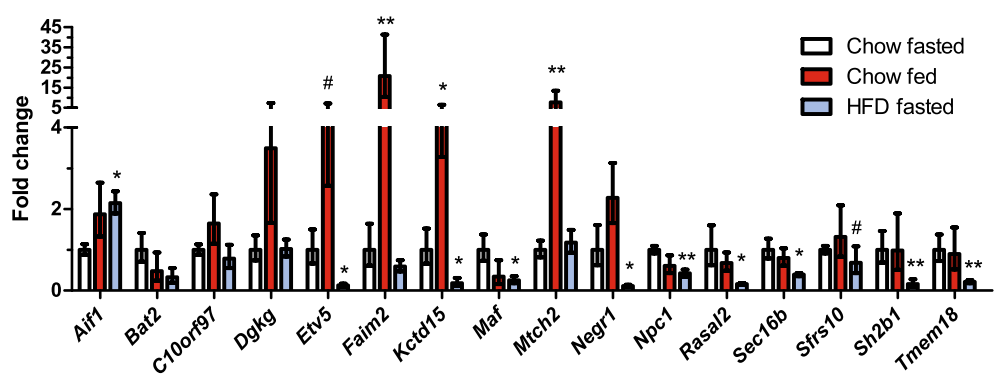

Figure 3 Regulation of GWAS obesity genes in adipose tissue in the fed state and by high fat feeding. Open bars represent the chow-fed, fasted controls; red bars represent the chow-fed non-fasted group; and blue bars represent the high fat fed group (fasted prior to tissue collection). The number of mice in the chow fasted, chow fed, and HFD fasted groups were: Aif1 (7, 8, 9), Bat2 (7, 6, 9), C100rf97 (7, 8, 5), $\operatorname{Dgkg}(7,6,4), \operatorname{Etv5}(7,4,8), \operatorname{Faim} 2(7,6,7), \operatorname{Kctd15}(7,4,9), \operatorname{Maf}(7,7,9), \operatorname{Mtch} 2(7,8,5), \operatorname{Negr1}(7,4,8), \operatorname{Npc1}(7,8,9), \operatorname{Rasal2}(7,7,9), \operatorname{Sec} 16 b(7,5,8)$, $\operatorname{Sfrs} 10(7,8,5), \operatorname{Sh} 261(7,5,9)$, and Tmem18 $(7,6,9)$, respectively. P-values vs. the chow-fed fasted controls: ${ }^{*}<0.05,{ }^{* *}<0.01,{ }^{*}<0.1$. 


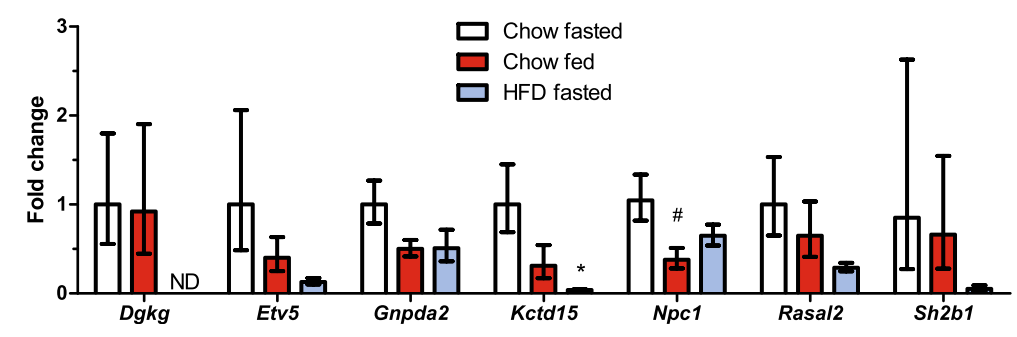

Figure 4 Regulation of GWAS obesity genes in the liver in the fed state and by high fat feeding. Open bars represent the chow-fed, fasted controls; red bars represent the chow-fed non-fasted group; and blue bars represent the high fat fed group (fasted prior to tissue collection). The number of mice in the chow fasted, chow fed, and HFD fasted groups were: Dgkg $(5,4,6)$, Etv5 $(7,5,3), \operatorname{Gnpda2}(7,5,6)$, $\operatorname{Kctd15}(5,4,4), \operatorname{Npc1}(7,5,5), \operatorname{Rasal2}(7,5,6)$, and $\operatorname{Sh} 261(7,5,6)$, respectively. P-values vs. the chow-fed fasted controls: ${ }^{*}<0.05,{ }^{*}<0.1 . N D=$ not detected.

We observed complex, tissue-dependent regulation of most of these new obesity genes. Only one gene, diacylglceryol kinase gamma $(D g k g)$, did not significantly change under any condition tested. However, given the role of this kinase in second messenger signalling, it is likely that it may not be physiologically regulated at the level of transcription but rather by activity of the enzyme. Note that this does not preclude the possibility that the GWAS SNPs may affect its basal transcription levels. The regulation of some genes was highly tissue specific. Four transcripts, Sfrs10, C10orf97, Pter, and Ctnnbl1 were increased in hypothalami of fed animals compared to fasted, but were not changed by this condition in other regions of the brain, liver or adipose tissue, or by high fat feeding in any tissue. Thus these genes may have unique functions in the hypothalamus regulating energy balance and the development of obesity. Similarly, Aif1 (allograft inflammatory factor 1) expression was increased by high fat feeding only in adipose tissue, whereas no differences in its expression were observed in the other tissues or in fed animals. It is unclear whether this reflects increased inflammation of adipose tissue in the high fat-fed mice (e.g. expression from increased amounts of inflammatory cells in the tissue), or whether this suggests that the role of Aif1 in obesity may be mediated via specific actions in adipose tissue.

In contrast to the above genes whose expression was affected by a single condition in a single tissue, the expression of other genes was more complex and altered in multiple tissues or by both conditions. Gnpda2 expression was increased in the hypothalamus and decreased in the liver of fed animals, whereas its expression did not differ in other regions of the brain or adipose tissue in fed vs. fasted animals. We did not detect any significant changes of this gene in response to high fat diet consumption, although another group has recently reported decreased expression of this gene in high fat diet-fed rats [29]. Several transcripts were decreased in the hypothalamus by high fat feeding and increased in the remainder of the brain in the fed state, with variable patterns in adipose tissue. Kctd15 regulation was the most consistent across tissues, with its expression being increased with feeding in hypothalamus, brain and adipose tissue (but not liver) and decreased by high fat diet consumption in hypothalamus, adipose tissue and liver (but not brain). A recent study has also found decreased Kctd15 expression in hypothalamus and adipose tissue of high fat-fed rats, although they did not observe reduced expression in liver [29].

We also observed a large range in the magnitude of the changes in gene expression, and for each transcript the magnitude of the change in expression was not the same in each tissue. For example, expression of Kctd15 was increased $>20$-fold in the brain of fed animals, but only by 2 - to 4 -fold in the hypothalamus and adipose tissue. These complex and tissue-dependent patterns of regulation in response to nutritional status suggest that these genes have important and perhaps distinct roles in several tissues.

Although each gene showed distinct patterns and magnitude of regulation across tissues and nutritional conditions, we observed striking consistency in the overall pattern of regulation by feeding and chronic high fat diet consumption. With few exceptions (Npc1 and Gnpda2 in liver, Figure 4), all genes regulated by feeding/fasting were upregulated in the non-fasted animals. This suggests that most transcripts respond to nutrient intake or increased nutrient levels, rather than acting as cues initiating food intake or promoting the mobilization of energy stores. Several transcription factors, co-activators, and factors affecting chromatin structure are known to increase expression of target genes in response to changes in cellular nutrient levels and energy status and thus may be important for the regulation of these genes [21-23]. Regulation of gene expression by feeding was prominent in the hypothalamus and remainder of brain, and also for some transcripts in adipose tissue. In fact, changes in response to feeding-fasting status accounted 
for nearly all the expression differences we observed in the brain; only one gene (Faim2) was regulated by high fat feeding in the brain. Interestingly, however, there was little overlap in the genes regulated by feeding between the hypothalamus and the remainder of the brain, suggesting that distinct nutrient-responsive regulatory pathways operate in various regions of the brain. In contrast, consumption of a high fat diet was associated with a reduction in expression of all of the regulated transcripts with the exception of Mtch2 in hypothalamus and Aif1 in adipose tissue. High fat diet consumption affected gene expression mainly in adipose tissue and the hypothalamus but not the rest of the brain, suggesting energy storage and homeostatic regulation of energy balance may be preferentially affected by today's obesogenic diets. This also suggests that high fat diets may predominantly down-regulate pathways important for normal adipose tissue function. Previous studies have shown reduced adipogenic gene expression in obese individuals [30-32].

Our findings further suggest that the effects of these genes on the development of obesity may occur in tissues in addition to the brain, which was previously suggested to be their likely site of action $[8,11]$. Consistent with this, Negr 1 has recently been shown to be expressed in adipose tissue and to be associated with gene expression networks [33]. Mtch2 expression in adipose tissue is increased in obese individuals [34] and has been shown to be increased in high fat-fed rats [29], although we did not observe changes in its expression in adipose tissue in response to high fat feeding (Figure 3). Somewhat surprisingly given its key role in whole-body metabolism and that high fat diets have previously been shown to regulate the hepatic expression of many genes [32], very few of the GWAS obesity genes had altered expression in the liver, suggesting that the metabolic processes of the liver may not play a significant role in the maintenance of whole body energy homeostasis. We also found that most of these genes except Etv5, Mtch2, Pter and Tmem 18 had relatively low to no detectable expression in soleus muscle (not shown). A recent study examining the expression of a partially-overlapping subset of GWAS obesity genes also found modest changes in expression of only a few genes in liver and muscle [29].

The nutritional regulation of these new obesity genes provides support for their potential role in the regulation of energy balance. These data have several important implications for studies examining the effects of the GWAS SNPs on gene regulation and ultimately the mechanisms by which these genes affect the development of obesity. The highly tissue-dependent patterns of regulation suggest that all tissues where a gene is expressed will need to be examined to determine whether the particular SNPs identified by the GWAS affect the expression of a gene. This is further highlighted by the complex patterns and variability in magnitude of expression changes for a transcript in different tissues. Analysis of the effects of the GWAS SNPs on gene expression in lymphocytes has been suggested since this is a readily accessible source of RNA, and differences in lymphocyte gene expression between lean and obese individuals have been detected [35]. This may be useful if the SNPs affect basal transcription of a gene, but will not be useful if the SNPs affect enhancer elements. Indeed, in a study examining the effects of diabetes-associated SNPs on gene expression, many correlations between genotype and were not observed in lymphocytes [36]. Similarly, SNPs affecting gene expression in lymphocytes were only associated with inflammatory and auto-immune diseases not with metabolic diseases [37]. Thus it may be very difficult to pinpoint the effects of these obesity GWAS SNPs on transcript levels. To understand the role of these genes in the development of obesity it will be necessary to fully understand the role of each gene in each physiologically relevant tissue, as they are regulated and thus may behave differently depending upon the tissue being examined.

Transcriptional regulatory elements can be located before, within, or even following a gene, and can be located at substantial distance (up to $1 \mathrm{Mb}$ ) from the gene [38]. Thus it is possible that the variants detected by the GWAS studies affect the regulation of other nearby genes, not just those that are closest to the SNP. We chose to focus our analyses on the genes reported by the GWAS studies as the most likely genes affected by the associated variants. The functions of many of these genes are not well described, and it is not clear how they may affect the development of obesity. We performed these studies to learn more about these genes, determine whether their expression patterns were consistent with them having a role in the regulation of body weight, and examine whether their expression is affected by known metabolic regulatory factors. While our data provide support for all the genes having a potential role in the development of obesity, they do not confirm that these are "the genes" nor do they exclude the possibility that the GWAS SNPs affect the regulation of other nearby genes.

Three of the obesity SNPs identified by Thorliefsson and colleagues [8] were found in gene dense regions where the SNP was not clearly more closely related to a single gene, and were consequently identified as being within gene clusters: SEC16B-RASAL2, SFRS10-ETV5$D G K G$, and NCR3-AIF1-BAT2. We examined the expression of the genes in each cluster with the hope of discovering regulatory patterns that may point to the more likely causative gene in each cluster. Unfortunately these studies provide little support favoring one of the 
genes over the other(s). All the genes were expressed in tissues relevant to the regulation of body weight. For the first cluster, both $S e c 16 b$ and Rasal2 were increased in the fed state in the brain and decreased by high fat feeding in adipose tissue. Neither was altered in the hypothalamus, while Rasal2 expression was also decreased in response to high fat feeding in the liver. The similar expression patterns make it difficult to prioritize one over the other as likely being the causative gene and also suggest that there may in fact be common regulatory elements affecting multiple genes in the region. The genes in the second and third clusters showed very different expression patterns from each other. In the second cluster, Sfrs10 expression was increased in the hypothalamus in fed mice but did not change in any of the other tissues. Etv 5 expression in the hypothalamus was decreased by high fat feeding and its expression increased in the brain and adipose tissue of fed animals. $D g k g$ expression, although relatively high in the hypothalamus and remainder of the brain, was not affected by fasting or the consumption of a high fat diet. For the third cluster, differential expression of Aif1 was detected in adipose tissue, where it was the only gene to increase in response to a high fat diet. In contrast, Bat2 expression was decreased by the high fat diet in hypothalamus, increased by feeding in brain, and was not changed in liver or adipose tissue. The expression of the Ncr3 pseudogene was not analyzed. Thus each member of the last two groups has a differential regulation in response to changing dietary conditions, which suggests that the causative variant(s) at these loci may affect just one of the genes rather than the coordinate regulation of multiple genes. However, for each cluster all the genes had potentially relevant changes in expression and it is unclear which of the genes is most likely to be affected by the GWAS SNP based on these analyses.

Recently other studies have reported expression patterns of some of these genes. One of these has shown that Tmem18 is expressed in most neurons [39]. These studies found no change in its expression in the hypothalamus or brainstem with prolonged (16 or 24 hour) fasting, 48 hour sucrose or fat ingestion or in response to chronic addition of $10 \%$ sucrose to the diet compared to ad-lib chow-fed mice [39]. Consistent with these findings, we saw no evidence of altered Tmem18 expression in response to chronic consumption of a high fatsucrose diet. In contrast, however, we found $\sim 8$-fold higher levels of Tmem18 in the brain of non-fasted animals (Figure 2). A recent study reproduced our finding of reduced expression of Etv 5 and $S h 2 b 1$ in the hypothalamus and Kctd15 in the hypothalamus and adipose tissue of high fat-fed animals [29]. In contrast, this study also found decreased expression of Kctd15 and Gnpda2 in the hypothalamus and Tmem18 in the liver, hypothalamus and soleus muscle, and increased expression of Mtch2 in adipose tissue and Pter in adipose tissue and liver of high fat-fed rats, which we did not observe [29]. The reasons for these discrepancies may relate to experimental design, such as differences in the species and strain studied; the diet used and its duration; the time of day of sacrifice; and the fasting conditions used, and require further investigation.

\section{Conclusions}

These studies have shown that the regulation of these new GWAS obesity genes in response to dietary conditions is complex and often tissue-dependent. Knowledge of the regulation of these genes will help in determining their role in obesity. These data provide supportive evidence for a role of these genes in the regulation of energy metabolism, but suggest that discovery of the mechanism by which the regulatory SNPs identified in the GWAS affect these genes will require tissue and context specific analysis.

\section{Additional file}

Additional file 1: Table S1. Primer sequences used in these studies.

\section{Abbreviations}

Aif1: Allograft inflammatory factor 1; BMl: Body mass index; Ctnnb/1: Catenin, beta-like 1; C10orf97: Chromosome 10 open reading frame $97 \mathrm{a}$;

Fam188a: Which is now known as Family with sequence similarity 188 member A; Ct: Cycle threshold; Dgkg: Diacylglycerol kinase gamma; Etv5: Ets variant 5; Faim2: Fas apoptotic inhibitory molecule 2; GWAS: Genome-wide association study; Gnpda2: Glucosamine 6 phosphate deaminase 2;

HFD: High fat diet; Bat2: HLA-B associated transcript 2; Mb: Million base pairs; Mtch2: Mitochondrial carrier homolog 2; Negr1: Neuronal growth regulator 1; Npc1: Niemann Pick type C1; Pter: Phosphotriesterase related;

Kctd15: Potassium channel tetramerisation domain containing 15; Rasal2: Ras protein activator like 2; Sec16b: SEC16 homolog b from S. cerevisiae;

SNP: Single nucleotide polymorphism; qPCR: Real-time quantitative reverse transcription PCR; Tra2b originally named Sfrs 10: Transformer 2 beta

homolog; Sh2b1: Sh2b adaptor protein 1; Tmem 18: Transmembrane protein 18; Maf: v-maf musculoaponeurotic fibrosarcoma oncogene homolog.

\section{Competing interests}

The authors confirm that they have no competing interests to disclose.

\section{Authors' contributions}

PY, SK and MMH conducted the study and participated in writing the manuscript. SMC designed the study, analyzed and interpreted the results and wrote the manuscript. All authors read and approved the final manuscript.

\section{Acknowledgements}

The authors would like to thank Ms. Shadi Mahmoodi and Mr. Akiff Manji for assistance with tissue collection and Dr. James D. Johnson for the use of the real time PCR equipment. These studies were supported by funding from the Michael Smith Foundation for Health Research (Cl-SCH-01423), the American Heart Association (0635234 N), the Canadian Diabetes Association (OG-2-08-2600-SC) and the Heart and Stroke Foundation of BC \& Yukon (SMC). SMC is Canada Research Chair in the Genetics of Obesity and Diabetes and a Michael Smith Foundation for Health Research Scholar. 
Received: 7 December 2011 Accepted: 21 April 2012 Published: 10 July 2012

\section{References}

1. Dina C, Meyre D, Gallina S, Durand E, Korner A, Jacobson P, Carlsson LM, Kiess W, Vatin V, Lecoeur C, Delplanque J, Vaillant E, Pattou F, Ruiz J, Weill J, Levy-Marchal C, Horber F, Potoczna N, Hercberg S, Le Stunff C, Bougneres P, Kovacs P, Marre M, Balkau B, Cauchi S, Chevre JC, Froguel P: Variation in FTO contributes to childhood obesity and severe adult obesity. Nat Genet 2007, 39:724-726.

2. Frayling $T M$, Timpson $N J$, Weedon $M N$, Zeggini $E$, Freathy RM, Lindgren $C M$, Perry JR, Elliott KS, Lango H, Rayner NW, Shields B, Harries LW, Barrett JC, Ellard S, Groves CJ, Knight B, Patch AM, Ness AR, Ebrahim S, Lawlor DA, Ring SM, Ben-Shlomo Y, Jarvelin MR, Sovio U, Bennett AJ, Melzer D, Ferrucci L, Loos RJ, Barroso I, Wareham NJ, Karpe F, Owen KR, Cardon LR, Walker M, Hitman GA, Palmer CN, Doney AS, Morris AD, Smith GD, Hattersley AT, McCarthy MI: A common variant in the FTO gene is associated with body mass index and predisposes to childhood and adult obesity. Science 2007, 316:889-894.

3. Scuteri A, Sanna S, Chen WM, Uda M, Albai G, Strait J, Najjar S, Nagaraja R, Orru M, Usala G, Dei M, Lai S, Maschio A, Busonero F, Mulas A, Ehret GB, Fink AA, Weder AB, Cooper RS, Galan P, Chakravarti A, Schlessinger D, Cao A, Lakatta E, Abecasis GR: Genome-Wide Association Scan Shows Genetic Variants in the FTO Gene Are Associated with Obesity-Related Traits. PLoS Genet 2007, 3:e115.

4. Speliotes EK, Willer CJ, Berndt SI, Monda KL, Thorleifsson G, Jackson AU, Allen HL, Lindgren CM, Luan J, Magi R, Randall JC, Vedantam S, Winkler TW, Qi L, Workalemahu T, Heid IM, Steinthorsdottir V, Stringham HM, Weedon MN, Wheeler E, Wood AR, Ferreira T, Weyant RJ, Segre AV, Estrada K, Liang L, Nemesh J, Park JH, Gustafsson S, Kilpelainen TO, Yang J, Bouatia-Naji N, Esko T, Feitosa MF, Kutalik Z, Mangino M, Raychaudhuri S, Scherag A, Smith AV, Welch R, Zhao JH, Aben KK, Absher DM, Amin N, Dixon AL, Fisher E, Glazer NL, Goddard ME, Heard-Costa NL, Hoesel V, Hottenga JJ, Johansson A, Johnson T, Ketkar S, Lamina C, Li S, Moffatt MF, Myers RH, Narisu N, Perry JR, Peters MJ, Preuss M, Ripatti S, Rivadeneira F, Sandholt C, Scott L, Timpson NJ, Tyrer JP, van Wingerden S, Watanabe RM, White CC, Wiklund F, Barlassina C, Chasman DI, Cooper MN, Jansson JO, Lawrence RW, Pellikka N, Prokopenko I, Shi J, Thiering E, Alavere H, Alibrandi MT, Almgren P, Arnold AM, Aspelund T, Atwood LD, Balkau B, Balmforth AJ, Bennett AJ, Ben-Shlomo Y, Bergman RN, Bergmann S, Biebermann H, Blakemore Al, Boes T, Bonnycastle LL, Bornstein SR, Brown MJ, Buchanan TA, Busonero F, Campbell H, Cappuccio FP, Cavalcanti-Proenca C, Chen YD, Chen CM, Chines PS, Clarke R, Coin L, Connell J, Day IN, Heijer MD, Duan J, Ebrahim S, Elliott P, Elosua R, Eiriksdottir G, Erdos MR, Eriksson JG, Facheris MF, Felix SB, Fischer-Posovszky P, Folsom AR, Friedrich N, Freimer NB, Fu M, Gaget S, Gejman PV, Geus EJ, Gieger C, Gjesing AP, Goel A, Goyette P, Grallert H, Grassler J, Greenawalt DM, Groves CJ, Gudnason V, Guiducci C, Hartikainen AL, Hassanali N, Hall AS, Havulinna AS, Hayward C, Heath AC, Hengstenberg C, Hicks AA, Hinney A, Hofman A, Homuth G, Hui J, lgl W, Iribarren C, Isomaa B, Jacobs KB, Jarick I, Jewell E, John U, Jorgensen T, Jousilahti P, Jula A, Kaakinen M, Kajantie E, Kaplan LM, Kathiresan S, Kettunen J, Kinnunen L, Knowles JW, Kolcic I, Konig IR, Koskinen S, Kovacs P, Kuusisto J, Kraft P, Kvaloy K, Laitinen J, Lantieri O, Lanzani C, Launer LJ, Lecoeur C, Lehtimaki T, Lettre G, Liu J, Lokki ML, Lorentzon M, Luben RN, Ludwig B, Manunta P, Marek D, Marre M, Martin NG, McArdle WL, McCarthy A, McKnight B, Meitinger T, Melander O, Meyre D, Midthjell K, Montgomery GW, Morken MA, Morris AP, Mulic R, Ngwa JS, Nelis M, Neville MJ, Nyholt DR, O'Donnell CJ, O'Rahilly S, Ong KK, Oostra B, Pare G, Parker AN, Perola M, Pichler I, Pietilainen KH, Platou CG, Polasek O, Pouta A, Rafelt S, Raitakari O, Rayner NW, Ridderstrale M, Rief W, Ruokonen A, Robertson NR, Rzehak P, Salomaa V, Sanders AR, Sandhu MS, Sanna S, Saramies J, Savolainen MJ, Scherag S, Schipf S, Schreiber S, Schunkert H, Silander K, Sinisalo J, Siscovick DS, Smit JH, Soranzo N, Sovio U, Stephens J, Surakka I, Swift AJ, Tammesoo ML, Tardif JC, Teder-Laving M, Teslovich TM, Thompson JR, Thomson B, Tonjes A, Tuomi T, van Meurs JB, van Ommen GJ, Vatin V, Viikari J, Visvikis-Siest S, Vitart V, Vogel Cl, Voight BF, Waite LL, Wallaschofski H, Walters GB, Widen E, Wiegand S, Wild SH, Willemsen G, Witte DR, Witteman JC, Xu J, Zhang Q, Zgaga L, Ziegler A, Zitting P, Beilby JP, Farooqi IS, Hebebrand J, Huikuri HV, James AL, Kahonen M, Levinson DF, Macciardi F, Nieminen MS, Ohlsson C, Palmer LJ,
Ridker PM, Stumvoll M, Beckmann JS, Boeing H, Boerwinkle E, Boomsma DI, Caulfield MJ, Chanock SJ, Collins FS, Cupples LA, Smith GD, Erdmann J, Froguel P, Gronberg H, Gyllensten U, Hall P, Hansen T, Harris TB, Hattersley AT, Hayes RB, Heinrich J, Hu FB, Hveem K, Illig T, Jarvelin MR, Kaprio J, Karpe F, Khaw KT, Kiemeney LA, Krude H, Laakso M, Lawlor DA, Metspalu A, Munroe PB, Ouwehand WH, Pedersen O, Penninx BW, Peters A, Pramstaller PP, Quertermous T, Reinehr T, Rissanen A, Rudan I, Samani NJ, Schwarz PE, Shuldiner AR, Spector TD, Tuomilehto J, Uda M, Uitterlinden A, Valle TT, Wabitsch M, Waeber G, Wareham NJ, Watkins H, Wilson JF, Wright AF, Zillikens MC, Chatterjee N, McCarroll SA, Purcell S, Schadt EE, Visscher PM, Assimes TL, Borecki IB, Deloukas P, Fox CS, Groop LC, Haritunians T, Hunter DJ, Kaplan RC, Mohlke KL, O'Connell JR, Peltonen L, Schlessinger D, Strachan DP, van Duijn CM, Wichmann HE, Frayling TM, Thorsteinsdottir U, Abecasis GR, Barroso I, Boehnke M, Stefansson K, North KE MIM, Hirschhorn JN, Ingelsson E, Loos RJ: Association analyses of 249,796 individuals reveal 18 new loci associated with body mass index. Nat Genet 2010, 42:937-948.

5. Loos RJ, Lindgren CM, Li S, Wheeler E, Zhao JH, Prokopenko I, Inouye M, Freathy RM, Attwood AP, Beckmann JS, Berndt SI, Jacobs KB, Chanock SJ, Hayes RB, Bergmann S, Bennett AJ, Bingham SA, Bochud M, Brown M, Cauchi S, Connell JM, Cooper C, Smith GD, Day I, Dina C, De S, Dermitzakis ET, Doney AS, Elliott KS, Elliott P, Evans DM, Sadaf Farooqi I, Froguel P, Ghori J, Groves CJ, Gwilliam R, Hadley D, Hall AS, Hattersley AT, Hebebrand J, Heid IM, Lamina C, Gieger C, Illig T, Meitinger T, Wichmann HE, Herrera B, Hinney A, Hunt SE, Jarvelin MR, Johnson T, Jolley JD, Karpe F, Keniry A, Khaw KT, Luben RN, Mangino M, Marchini J, McArdle WL, McGinnis R, Meyre D, Munroe PB, Morris AD, Ness AR, Neville MJ, Nica AC, Ong KK, O'Rahilly S, Owen KR, Palmer CN, Papadakis K, Potter S, Pouta A, Qi L, Randall JC, Rayner NW, Ring SM, Sandhu MS, Scherag A, Sims MA, Song K, Soranzo N, Speliotes EK, Syddall HE, Teichmann SA, Timpson NJ, Tobias JH, Uda M, Vogel Cl, Wallace C, Waterworth DM, Weedon MN, Willer CJ, Wraight, Yuan X, Zeggini E, Hirschhorn JN, Strachan DP, Ouwehand WH, Caulfield MJ, Samani NJ, Frayling TM, Vollenweider P, Waeber G, Mooser V, Deloukas P, McCarthy MI, Wareham NJ, Barroso I, Kraft P, Hankinson SE, Hunter DJ, Hu FB, Lyon HN, Voight BF, Ridderstrale M, Groop L, Scheet P, Sanna S, Abecasis GR, Albai G, Nagaraja R, Schlessinger D, Jackson AU, Tuomilehto J, Collins FS, Boehnke M, Mohlke KL: Common variants near MC4R are associated with fat mass, weight and risk of obesity. Nat Genet 2008, 40:768-775.

6. Chambers JC, Elliott P, Zabaneh D, Zhang W, Li Y, Froguel P, Balding D, Scott J, Kooner JS: Common genetic variation near MC4R is associated with waist circumference and insulin resistance. Nat Genet 2008, 40:716-718.

7. Hofker M, Wijmenga C: A supersized list of obesity genes. Nat Genet 2009, 41:139-140

8. Thorleifsson G, Walters GB, Gudbjartsson DF, Steinthorsdottir V, Sulem P, Helgadottir A, Styrkarsdottir U, Gretarsdottir S, Thorlacius S, Jonsdottir I, Jonsdottir T, Olafsdottir EJ, Olafsdottir GH, Jonsson T, Jonsson F, Borch-Johnsen $K$, Hansen T, Andersen G, Jorgensen T, Lauritzen T, Aben KK, Verbeek AL, Roeleveld N, Kampman E, Yanek LR, Becker LC, Tryggvadottir L, Rafnar T, Becker DM, Gulcher J, Kiemeney LA, Pedersen O, Kong A, Thorsteinsdottir U, Stefansson K: Genome-wide association yields new sequence variants at seven loci that associate with measures of obesity. Nat Genet 2009, 41:18-24.

9. Meyre D, Delplanque J, Chevre JC, Lecoeur C, Lobbens S, Gallina S, Durand E, Vatin V, Degraeve F, Proenca C, Gaget S, Korner A, Kovacs P, Kiess W, Tichet J, Marre M, Hartikainen AL, Horber F, Potoczna N, Hercberg S, Levy-Marchal C, Pattou F, Heude B, Tauber M, McCarthy MI, Blakemore Al, Montpetit A, Polychronakos C, Weill J, Coin LJ, Asher J, Elliott P, Jarvelin MR, Visvikis-Siest S, Balkau B, Sladek R, Balding D, Walley A, Dina C, Froguel P: Genome-wide association study for early-onset and morbid adult obesity identifies three new risk loci in European populations. Nat Genet 2009, 41:157-159.

10. Liu YJ, Liu XG, Wang L, Dina C, Yan H, Liu JF, Levy S, Papasian CJ, Drees BM, Hamilton JJ, Meyre D, Delplanque J, Pei YF, Zhang L, Recker RR, Froguel P, Deng HW: Genome-wide association scans identified CTNNBL1 as a novel gene for obesity. Hum Mol Genet 2008, 17:1803-1813.

11. Willer CJ, Speliotes EK, Loos RJ, Li S, Lindgren CM, Heid IM, Berndt SI, Elliott AL, Jackson AU, Lamina C, Lettre G, Lim N, Lyon HN, McCarroll SA, Papadakis K, Qi L, Randall JC, Roccasecca RM, Sanna S, Scheet P, Weedon MN, Wheeler E, Zhao JH, Jacobs LC, Prokopenko I, Soranzo N, 
Tanaka T, Timpson NJ, Almgren P, Bennett A, Bergman RN, Bingham SA, Bonnycastle LL, Brown M, Burtt NP, Chines P, Coin L, Collins FS, Connell JM, Cooper C, Smith GD, Dennison EM, Deodhar P, Elliott P, Erdos MR, Estrada K, Evans DM, Gianniny L, Gieger C, Gillson CJ, Guiducci C, Hackett R, Hadley D, Hall AS, Havulinna AS, Hebebrand J, Hofman A, Isomaa B, Jacobs KB, Johnson T, Jousilahti P, Jovanovic Z, Khaw KT, Kraft P, Kuokkanen M, Kuusisto J, Laitinen J, Lakatta EG, Luan J, Luben RN, Mangino M, McArdle WL, Meitinger T, Mulas A, Munroe PB, Narisu N, Ness AR, Northstone K, O'Rahilly S, Purmann C, Rees MG, Ridderstrale M, Ring SM, Rivadeneira F, Ruokonen A, Sandhu MS, Saramies J, Scott LJ, Scuteri A, Silander K, Sims MA, Song K, Stephens J, Stevens S, Stringham HM, Tung YC, Valle TT, Van Duijn CM, Vimaleswaran KS, Vollenweider P, Waeber G, Wallace C, Watanabe RM, Waterworth DM, Watkins N, Witteman JC, Zeggini E, Zhai G, Zillikens MC, Altshuler D, Caulfield MJ, Chanock SJ, Faroogi IS, Ferrucci L, Guralnik JM, Hattersley AT, Hu FB, Jarvelin MR, Laakso M, Mooser V, Ong KK, Ouwehand WH, Salomaa V, Samani NJ, Spector TD, Tuomi T, Tuomilehto J, Uda M, Uitterlinden AG, Wareham NJ, Deloukas P, Frayling TM, Groop LC, Hayes RB, Hunter DJ, Mohlke KL, Peltonen L, Schlessinger D, Strachan DP, Wichmann HE, McCarthy MI, Boehnke M, Barroso I, Abecasis GR, Hirschhorn JN: Six new loci associated with body mass index highlight a neuronal influence on body weight regulation. Nat Genet 2009, 41:25-34.

12. Walley AJ, Asher JE, Froguel P: The genetic contribution to non-syndromic human obesity. Nat Rev Genet 2009, 10:431-442.

13. Cordeira JW, Frank L, Sena-Esteves M, Pothos EN, Rios M: Brain-derived neurotrophic factor regulates hedonic feeding by acting on the mesolimbic dopamine system. J Neurosci 2010, 30:2533-2541.

14. Rankinen T, Zuberi A, Chagnon YC, Weisnagel SJ, Argyropoulos G, Walts B, Perusse L, Bouchard C: The Human Obesity Gene Map: The 2005 Update. Obesity 2006, 14:529-644

15. Ren D, Li M, Duan C, Rui L: Identification of SH2-B as a key regulator of leptin sensitivity, energy balance, and body weight in mice. Cell Metab 2005, 2:95-104.

16. Farooqi IS, O'Rahilly S: Mutations in ligands and receptors of the leptin-melanocortin pathway that lead to obesity. Nat Clin Pract Endocrinol Metab 2008, 4:569-577.

17. Stutzmann F, Vatin V, Cauchi S, Morandi A, Jouret B, Landt O, Tounian P, Levy-Marchal C, Buzzetti R, Pinelli L, Balkau B, Horber F, Bougneres P, Froguel $P$, Meyre D: Non-synonymous polymorphisms in melanocortin-4 receptor protect against obesity: the two facets of a Janus obesity gene. Hum Mol Genet 2007, 16:1837-1844

18. Han JC, Liu QR, Jones M, Levinn RL, Menzie CM, Jefferson-George KS, Adler-Wailes DC, Sanford EL, Lacbawan FL, Uhl GR, Rennert OM, Yanovski JA: Brain-derived neurotrophic factor and obesity in the WAGR syndrome. N Engl J Med 2008, 359:918-927.

19. Morris $\mathrm{DL}$, Rui $\mathrm{L}$ : Recent advances in understanding leptin signaling and leptin resistance. Am J Physiol Endocrinol Metab 2009,

297:E1247-E1259.

20. Ragvin A, Moro E, Fredman D, Navratilova P, Drivenes O, Engstrom PG, Alonso ME, Mustienes Ede L, Skarmeta JL, Tavares MJ, Casares F, Manzanares M, van Heyningen V, Molven A, Njolstad PR, Argenton F, Lenhard B, Becker TS: Long-range gene regulation links genomic type 2 diabetes and obesity risk regions to HHEX, SOX4, and IRX3. Proc Natl Acad Sci U S A 2010, 107:775-780.

21. Canto C, Auwerx J: PGC-1alpha, SIRT1 and AMPK, an energy sensing network that controls energy expenditure. Curr Opin Lipido/ 2009, 20:98-105.

22. Gross DN, van den Heuvel AP, Birnbaum MJ: The role of FoxO in the regulation of metabolism. Oncogene 2008, 27:2320-2336.

23. Moreno M, Lombardi A, Silvestri E, Senese R, Cioffi F, Goglia F, Lanni A de Lange P: PPARs: Nuclear Receptors Controlled by, and Controlling, Nutrient Handling through Nuclear and Cytosolic Signaling. PPAR Res 2010, 2010:435689

24. Redinger RN: Fat storage and the biology of energy expenditure. Trans/ Res 2009, 154:52-60.

25. Fredriksson R, Hagglund M, Olszewski PK, Stephansson O, Jacobsson JA, Olszewska AM, Levine AS, Lindblom J, Schioth HB: The obesity gene, FTO, is of ancient origin, up-regulated during food deprivation and expressed in neurons of feeding-related nuclei of the brain. Endocrinology 2008, 149:2062-2071.
26. Hollyoake M, Campbell RD, Aguado B: NKp30 (NCR3) is a pseudogene in 12 inbred and wild mouse strains, but an expressed gene in Mus caroli. Mol Biol Evol 2005, 22:1661-1672.

27. Yuan JS, Reed A, Chen F, Stewart CN Jr: Statistical analysis of real-time PCR data. BMC Bioinformatics 2006, 7:85.

28. Lenard NR, Berthoud HR: Central and peripheral regulation of food intake and physical activity: pathways and genes. Obesity (Silver Spring) 2008, 16(Suppl 3):S11-S22.

29. Gutierrez-Aguilar R, Kim DH, Woods SC, Seeley RJ: Expression of new loci associated with obesity in diet-induced obese rats: from genetics to physiology. Obesity (Silver Spring) 2012, 20:306-312.

30. Nadler ST, Stoehr JP, Schueler KL, Tanimoto G, Yandell BS, Attie AD: The expression of adipogenic genes is decreased in obesity and diabetes mellitus. Proc Natl Acad Sci U S A 2000, 97:11371-11376.

31. Diraison F, Dusserre E, Vidal H, Sothier M, Beylot M: Increased hepatic lipogenesis but decreased expression of lipogenic gene in adipose tissue in human obesity. Am J Physiol Endocrinol Metab 2002, 282:E46-E51.

32. Kim S, Sohn I, Ahn Jl, Lee KH, Lee YS: Hepatic gene expression profiles in a long-term high-fat diet-induced obesity mouse model. Gene 2004 340:99-109.

33. Walley AJ, Jacobson P, Falchi M, Bottolo L, Andersson JC, Petretto E, Bonnefond A, Vaillant E, Lecoeur C, Vatin V, Jernas M, Balding D, Petteni M Park YS, Aitman T, Richardson S, Sjostrom L, Carlsson LM, Froguel P: Differential coexpression analysis of obesity-associated networks in human subcutaneous adipose tissue. Int J Obes (Lond) 2012, 36:137-147.

34. Kulyte A, Ryden M, Mejhert N, Dungner E, Sjolin E, Arner P, Dahlman I: MTCH2 in human white adipose tissue and obesity. J Clin Endocrinol Metab 2011, 96:E1661-E1665.

35. Ghosh S, Dent R, Harper ME, Gorman SA, Stuart JS, McPherson R: Gene expression profiling in whole blood identifies distinct biological pathways associated with obesity. BMC Med Genomics 2010, 3:56

36. Sharma NK, Langberg KA, Mondal AK, Elbein SC, Das SK: Type 2 diabetes (T2D) associated polymorphisms regulate expression of adjacent transcripts in transformed lymphocytes, adipose, and muscle from Caucasian and African-American subjects. J Clin Endocrinol Metab 2011, 96:E394-E403.

37. Nicolae DL, Gamazon E, Zhang W, Duan S, Dolan ME, Cox NJ: Traitassociated SNPs are more likely to be eQTLs: annotation to enhance discovery from GWAS. PLOS Genet 2010, 6:e1000888.

38. Maston GA, Evans SK, Green MR: Transcriptional regulatory elements in the human genome. Annu Rev Genomics Hum Genet 2006, 7:29-59.

39. Almen MS, Jacobsson JA, Shaik JH, Olszewski PK, Cedernaes J, Alsio J, Sreedharan S, Levine AS, Fredriksson R, Marcus C, Schioth HB: The obesity gene, TMEM18, is of ancient origin, found in majority of neuronal cells in all major brain regions and associated with obesity in severely obese children. BMC Med Genet 2010, 11:58

doi:10.1186/1743-7075-9-65

Cite this article as: Yoganathan et al:: Nutritional regulation of genome-wide association obesity genes in a tissue-dependent manner. Nutrition \& Metabolism 2012 9:65.

\section{Submit your next manuscript to BioMed Central and take full advantage of:}

- Convenient online submission

- Thorough peer review

- No space constraints or color figure charges

- Immediate publication on acceptance

- Inclusion in PubMed, CAS, Scopus and Google Scholar

- Research which is freely available for redistribution 